\title{
Green care in first-episode psychosis: short report of a mixed-methods evaluation of a 'woodland group' in an early intervention service
}

\author{
Sharon Cuthbert, ${ }^{1} \odot$ Harriet Sharp, ${ }^{1}$ Clio Berry ${ }^{1,2} \odot$
}

BJPsych Bulletin (2021) 45, 235-237, doi:10.1192/bjb.2021.54

\author{
${ }^{1}$ Sussex Partnership NHS Foundation \\ Trust, Hove, UK; ${ }^{2}$ Brighton and Sussex \\ Medical School, Brighton, UK \\ Correspondence to Sharon Cuthbert \\ (sharon.cuthbert@sussexpartnership. \\ nhs.uk) \\ First received 18 Nov 2020, final revision \\ 4 Feb 2021, accepted 21 Apr 2021 \\ (c) The Author(s), 2021. Published by \\ Cambridge University Press on behalf of \\ the Royal College of Psychiatrists. This is \\ an Open Access article, distributed \\ under the terms of the Creative \\ Commons Attribution licence (http:// \\ creativecommons.org/licenses/by/ \\ 4.0/), which permits unrestricted \\ re-use, distribution, and reproduction \\ in any medium, provided the original \\ work is properly cited.
}

\begin{abstract}
Aims and method In the context of increasing recognition of the role of nature in well-being, but limited evidence for specific patient groups, we describe a mixedmethods evaluation of a 10-week green care intervention (a woodland group) for 18- to 30-year-olds who had experienced a first episode of psychosis. Data were collected using the Questionnaire on the Process of Recovery (QPR), semi-structured service evaluation questionnaires, the NHS Friends and Family Test (FFT), and focus group analysis.
\end{abstract}

Results All participants present at week $10(n=5)$ would recommend this group to others; 4/8 participants showed reliable improvement on QPR outcome measures. Thematic analysis identified themes of connection with nature and others, development of a sense of well-being and 'peacefulness' and new perspectives on psychotic experience.

Clinical implications This small retrospective evaluation describes patient-reported benefits, feasibility and acceptability of green care interventions within early intervention in psychosis services (EIS).

Keywords Outcome studies; out-patient treatment; psychosocial interventions; qualitative research; psychotic disorders.
Early intervention services (EIS) aim to reduce symptomatic periods and improve developmental and social trajectories for those who have experienced a first episode of psychosis (FEP). ${ }^{1}$ Full recovery and therapeutic engagement may be difficult to achieve. ${ }^{2-4}$ Green care uses natural environments to facilitate improvements in well-being, with growing evidence to support effectiveness in the general population. ${ }^{5,6}$ Evaluations suggest that people with mental health problems may benefit proportionally more from such nature-based care. ${ }^{7}$ Accessing green space may mitigate health inequalities closely tied to severe and enduring mental illness (SMI), ${ }^{8,9}$ including for young people, among whom nature 'connectedness' is low. ${ }^{10}$ Groups in natural spaces may also confer potential advantages for therapeutic engagement and work. ${ }^{11-13}$ However, there is limited evidence for green care for those with SMI ${ }^{14,15}$ and, to our knowledge, none in FEP. Green care is a 'complex intervention', combining psychological work, physical activity and social interactions, ${ }^{16}$ so our study used a mixed-methods approach, as recommended by the Medical Research Council. ${ }^{17}$ This mixed-methods evaluation considers potential benefits and barriers encountered in a green care programme delivered in an EIS.

\section{The intervention}

The woodland group was facilitated by Circle of Life Rediscovery (CLR), commissioned by Sussex Partnership
NHS Foundation Trust for 10 weekly half-day sessions. Two CLR staff prepared and attended groups, collaborating with EIS staff who facilitated transport and supported individuals (up to 15), with an overall staff:participant ratio of at least $1: 3$.

The group included a short walk, refreshments, contemplative time and activities such as learning about plants and habitats, maintaining the woodland area and cooking.

All participants were aged between 18-30 and had experienced FEP, some demonstrating active psychotic symptoms. Target problems included isolation, anxiety and depression.

\section{Ethics and consent}

This study was conducted as a service evaluation and did not require research ethics approval. All participants gave written consent for data to be collected and used within evaluations of the service.

\section{Data collection and analysis}

Participants completed the 15-item Questionnaire about the Process of Recovery (QPR) at weeks 1, 3, 6 and 10. The QPR has good internal consistency, high test-retest reliability and convergent validity. ${ }^{18,19}$ 'Reliable change', an estimate of statistical significance of change in outcome scores, was calculated using the Jacobson-Truax formula with published 
Cronbach's alpha and standard deviation. ${ }^{20,21}$ Participants in the final session also completed a semi-structured service evaluation questionnaire and the NHS Friends and Family Test (FFT). ${ }^{22}$

Qualitative data were invited through free-text portions of the evaluation questionnaire and through intervention summaries completed by participants and staff. A $20 \mathrm{~min}$ focus group $(n=7)$ was convened in the final session, facilitated by the group leader and transcribed by the first author. All three authors independently performed thematic analysis of the data.

\section{Results}

The QPR 5-point Likert scale ranges from 1 (disagree strongly) to 5 (agree strongly). Mean QPR scores increased from $3.4(n=$ $3)$ at week 1 to 3.8 at week $10(n=8)$. Four patients showed reliable improvement and one showed reliable deterioration for those with data at two time points $(n=8)$.

All participants present at week $10(n=5)$ recommended the group on the FFT. ${ }^{22}$

Results of the evaluation questionnaire (at week 10) are shown in Table 1.

All authors were concordant on two higher-order themes from the qualitative data. The first was connection with others and nature. Participants described reduced isolation and improved relationships:

'It's therapeutic to sit round a fire with other people [. . .] it's nice to feel connected.'

'The difference [...] I'm not isolated [...] I can feel normal. You go to doctor's appointments, you're not part of the 9-5 but we are still here.'

'I feel [...] awe/curiosity for the natural world.'

\begin{tabular}{|c|c|}
\hline & $\begin{array}{c}\text { Mean } \\
(\text { median })^{\mathrm{a}}\end{array}$ \\
\hline I feel more connected to the world around me & $4.4(4)$ \\
\hline $\begin{array}{l}\text { My emotional and psychological well-being has } \\
\text { improved }\end{array}$ & $4.3(4)$ \\
\hline My recovery has been helped & $4.1(4)$ \\
\hline I have found ways to manage difficult emotions & $3.5(3.5)$ \\
\hline I have found things that can help me in a crisis & $3.8(4)$ \\
\hline $\begin{array}{l}\text { I have connected with other people in a positive } \\
\text { way }\end{array}$ & $4.8(5)$ \\
\hline I have had some difficult social encounters & $3.4(3)$ \\
\hline $\begin{array}{l}\text { I have been more worried about the world around } \\
\text { me }\end{array}$ & $2.5(2.5)$ \\
\hline I feel more hopeful & $3.9(4)$ \\
\hline $\begin{array}{l}\text { I have felt more confident about going to new } \\
\text { places }\end{array}$ & $3.4(4)$ \\
\hline I have learnt new skills & $4.3(4)$ \\
\hline I have felt more confident about meeting people & $4(4)$ \\
\hline I have made friendships which may continue & $4.1(4)$ \\
\hline
\end{tabular}

a. Scores are on a 5-point Likert scale: 1, 'strongly disagree', 5 'strongly agree'.
A second overarching theme was of positive change in self, including skills development and emotional change. This was expressed as feeling 'confident to do things' or 'I enjoyed the cooking [...] it helped distract me more, and it's skills I have used at home'. Participants appreciated creativity and the chance to 'take something away' - including physical objects, memories and new skills. They described feelings of calmness: ' $100 \%$ impact. I feel better about myself [...] I feel supported, I feel able. I have found stillness, calmness [...]. It is very healing. Staff noted that participants appeared more relaxed in the woodland group than in other settings.

Particularly relevant to this group were repeated suggestions that the group enabled changed perspectives on psychosis. One participant wrote '[it] showed me what's real in my [...] psychotic state' and another '[it] helps me understand other people's perception of psychosis'.

Barriers to participation included short sessions and poor weather. No adverse events, near misses or concerns regarding risky behaviour were reported.

\section{Discussion and conclusions}

This evaluation offers promise for green care as an intervention in FEP. Unusually, group attendance improved over time and all participants recommended it. Sequential QPR measures showed positive trends across all recovery domains; additionally, attendees described increased insight and contextualisation of difficulties, alongside distraction from problematic symptoms. Participants spontaneously discussing their beliefs and experiences, potentially enabled by the attention-restoring and stress-reducing properties of the woodland environment, seems to have encouraged reflection and reality testing. The group was therapeutic, with features of universality, development of socialising skills and interpersonal learning. ${ }^{23}$

Feedback for improvement was sparse. The location, with associated travelling costs, and the intensive EIS staff involvement were cited as barriers to re-commissioning. CLR staff reported that the 'scaffolding' provided by NHS support enabled them to facilitate the group. Without this early input, successful engagement of this patient group seems less likely. Full economic (and carbon) costings, including staff resource, should be part of future evaluations and commissioning for such groups, as within the wider social prescribing context. ${ }^{24}$

The findings are limited by small sample size, areas of incomplete data and use of patient-reported outcome scales only. We have no data from those who chose not to attend the intervention. Although qualitative analysis allows themes to emerge from the data, defining components and aspects of the intervention which may be poorly understood, ${ }^{25}$ thematic saturation was likely not reached, and participants may have felt constrained by facilitator presence in the focus group. Further exploration of the increased reflective ability on personal psychotic experiences that participants reported feeling within the grounding and supported woodland setting would be particularly helpful.

Initiatives to boost green prescribing are expanding. ${ }^{26}$ This is a preliminary report, indicating promising features 
for green care as a sustainable intervention in EIS. As a community-based intervention it is empowering and there is potential benefit from developing nature connectedness, which is associated with increased conservation behaviours. $^{27}$ Although further exploration of the benefits of green care, including its influence on psychotic experience and longer-term outcomes, is needed, the experiences this group describe suggest that nurturing opportunities for patients to access nature could promote recovery and rebalance relationships with the environment.

\section{About the authors}

Sharon Cuthbert is a consultant psychiatrist with Sussex Partnership NHS Foundation Trust, based at Millview Hospital, Hove, UK. Harriet Sharp is an Academic Clinical Fellow in psychiatry with Sussex Partnership NHS Foundation Trust, Hove, UK. Clio Berry is a lecturer in Healthcare Evaluation and Improvement in Primary Care and Public Health at Brighton and Sussex Medical School, Brighton, UK.

\section{Data availability}

The data that support the findings of this study are available on request from the corresponding author. The data are not publicly available owing to potential compromise of the privacy of those who contributed.

\section{Acknowledgements}

Thanks to Marina Robb, Circle of Life Rediscovery, and to the Hailsham Early Intervention Service.

\section{Author contributions}

S.C. gathered and analysed evaluation and focus group data and produced the first draft. H.S. and C.B. contributed to qualitative analysis and contributed to subsequent drafts. All authors meet ICJME criteria for authorship.

\section{Funding}

This research received no specific grant from any funding agency, commercial or not-for-profit sectors.

\section{Declaration of interest}

None.

\section{References}

1 McGorry PD, Killackey E, Yung A. Early intervention in psychosis: concepts, evidence and future directions. World Psychiatry 2008; 7: 148-56.

2 Hodgekins J, Birchwood M, Christopher R, Marshall M, Coker S, Everard $L$, et al. Investigating trajectories of social recovery in individuals with first-episode psychosis: a latent class growth analysis. $\mathrm{Br} \mathrm{J}$ Psychiatry 2015; 207: 536-43.

3 O'Brien A, Fahmy R, Singh S. Disengagement from mental health services: a literature review. Psychiatr Epidemiol 2009; 44: 558-68.

4 Morrison AP, Pyle M, Maughan D, Johns L, Freeman D, Broome MR, et al. Antipsychotic medication versus psychological intervention versus a combination of both in adolescents with first-episode psychosis (MAPS): a multicentre, three-arm, randomised controlled pilot and feasibility study. Lancet Psychiatry 2020; 7: 788-800.

5 Richardson M, McEwan K. 30 days wild and the relationships between engagement with nature's beauty, nature connectedness and wellbeing. Front Psychol 2018; 9: 1500.
6 Lovell R, Depledge M, Maxwell S. Health and the Natural Environment: A Review of Evidence, Policy, Practice and Opportunities for the Future. Department for Environment, Food and Rural Affairs, 2019

7 Bragg R, Atkins G. A Review of Nature-Based Interventions for Mental Health Care (Natural England Commissioned Reports NECR204). Natural England, 2016.

8 Grant M. Health Inequalities and Determinants in the Physical Urban Environment. WHO Collaborating Centre for Healthy Cities, 2010.

9 WHO Regional Office for Europe. Addressing the Social Determinants of Health: the Urban Dimension and the Role of Local Government. WHO, 2012.

10 Richardson $M$, Hunt $A$, Hinds J, Bragg $R$, Fido $D$, Petronzi $D$, et al. A measure of nature connectedness for children and adults: validation, performance and insights. Sustainability 2019; 11: 3250

11 Ulrich R, Simons RF, Losito BD, Fiorito E, Miles MA, Zelzon M. Stress recovery during exposure to natural and urban environments. J Env Psychol 1991; 11: 201-30

12 Ohly H, White MP, Wheeler BW, Bethel A, Ukoumunne OC, Nikolaou $\mathrm{V}$, et al. Attention restoration theory: a systematic review of the attention restoration potential of exposure to natural environments. J Toxicol Env Health 2016; 19: 305-43.

13 Cooley SJ, Jones CR, Kurtz A, Robertson N. 'Into the wild': a metasynthesis of talking therapy in natural outdoor spaces. Clin Psychol Rev 2020; 77: 101841 .

14 Buckley RC, Brough P. Nature, eco and adventure therapies for mental health and chronic disease. Public Health 2017; 5: 220.

15 Cuthbert S, Kellas A, Page L. Green care in psychiatry. Br J Psychiatry 2021; 218: 73-4.

16 Dures E, Rumsey N, Morris M, Gleeson K. Mixed methods in health psychology. J Health Psychol 2010; 16: 332-41.

17 Craig P, Dieppe P, Macintyre S, Michie S, Nazareth I, Petticrew M Developing and Evaluating Complex Interventions. Medical Research Council, 2019

18 Williams J, Leamy M, Pesola F, Bird V, Boutillier C, Slade $M$ et al. Psychometric evaluation of the Questionnaire about the Process of Recovery (QPR). Br J Psychiatry 2015; 207: 551-5.

19 Law H, Neil ST, Dunn G, Morrison AP. Psychometric properties of the Questionnaire about the Process of Recovery (QPR). Schizophr Res 2014; 156: 184-9.

20 Zahra D. RCI Calculator. Daniel Zahra, 2010 (https://www.daniel-zahra. com/publications).

21 Jacobson NS, Truax P. Clinical significance: a statistical approach to defining meaningful change in psychotherapy research. In Methodological Issues \& Strategies in Clinical Research (ed AE Kazdin): 631-48. American Psychological Association, 1992. Available from: https://doi.org/10. 1037/10109-042.

22 NHS England. Using the Friends and Family Test to Improve Patient Experience (NHS England and NHS Improvement Guidance). NHS England, 2019.

23 Yalom ID. The Theory and Practice of Group Psychotherapy (4th edn). Basic Books, 1995.

24 National Association of Link Workers. Getting to Know the Link Worker Workforce: Understanding Link Workers Knowledge, Skills, Experiences and Support Needs. NALW, 2019 (https://www.nalw.org.uk/wp-content/ uploads/2019/06/Released_NALW_link-worker-report_March-2019 updated.pdf).

25 Campbell M, Fitzpatric R, Hanes A, Kinmonth AL, Snadercock $P$, Spiegelhalter D, et al. Framework for design and evaluation of complex interventions to improve health. BMJ 2000; 321: 694.

26 Eustice G. George Eustice Speech on Environmental Recovery: 20 July 2020. Department for Environment, Food \& Rural Affairs, 2020 (https://www.gov.uk/government/speeches/george-eustice-speechon-environmental-recovery-20-july-2020)

27 Mackay CL, Schmitt MT. Do people who feel connected to nature do more to protect it? A meta analysis. J Env Psychol 2019; 65: 101323.

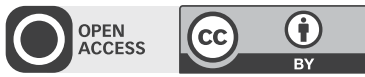

